\title{
DA EXPERIÊNCIA À ANÁLISE ARQUIVÍSTICAS: Um estudo de caso realizado no Arquivo do Fórum Regional Desembargador José Flóscolo da Nóbrega (João Pessoa - Paraíba)
}

\author{
Wellington da Silva Gomes \\ Mestrando em Ciência da Informação \\ Programa de Pós-Graduação em Ciência da Informação \\ Universidade Federal da Paraíba \\ wbless07@gmail.com \\ Manuela Eugênio Maia \\ Doutora em Ciência da Informação \\ Professora do Curso de Arquivologia \\ Universidade Estadual da Paraíba \\ manuelamaia@gmail.com
}

\section{Resumo}

A complexa atividade de gestão de documentos abrange todo o espaço institucional de produção, organização, controle e uso de documentação arquivística. O objetivo do estudo foi analisar as práticas arquivísticas desempenhadas no período de atuação de estágio (entre 22 de novembro de 2014 e 22 de novembro de 2016), bem como as orientações realizadas no Arquivo do Fórum Regional Desembargador José Flóscolo da Nóbrega, localizado no município de João Pessoa. Metodologicamente, a investigação assumiu caráter descritivo e exploratório; sua natureza aplicada, lançou propostas na melhoria das práticas do arquivo. Usou-se como instrumento de coleta de dados a observação participante, o registro diário e o relatório de atividades realizadas. Interpretando a realidade à luz dos autores já consolidados na área da Arquivologia, o estudo ancorou-se numa abordagem qualitativa. Como resultado, foi apresentado a descrição das técnicas e dos procedimentos adotados na realização das atividades, subsidiados pelo campo teórico da Arquivologia, trazendo precisão e tramitação do fluxo documental do arquivo do referido fórum. Conclui-se que o fazer arquivístico não se limita apenas à implementação de procedimentos e de métodos no gerenciamento da informação. A busca por melhores condições de trabalho e o reconhecimento nas instituições é uma luta constante dos arquivistas, fazendo parte ainda da realidade brasileira.

\section{Palavras-chave}

Arquivo do Tribunal de Justiça da Paraíba. Fórum Desembargador José Flóscolo da Nóbrega. Gestão de documentos.

\section{INTRODUÇÃO}

Quiçá seja lugar comum relatar as práticas realizadas em arquivos. Contudo, cada texto é único e apresenta um ponto de vista sobre suas peculiaridades. Ademais, torna-se um exercício de escrita e de análise que faz parte do amadurecimento do processo de interlocução acadêmico. Nesse sentido, compartilhar a nossa realidade em um dado contexto pode vir a contribuir com outros profissionais em atividade e acreditamos ser um ponto fundamental da participação em periódicos de cunho científico. Nessa direção, justificamos que o esse relato tem a sua relevância no sentido de apresentar à comunidade arquivística as práticas vivenciadas e as reflexões acerca da nossa atuação frente ao Arquivo do Fórum Desembargador José Flóscolo da Nóbrega, 
localizado na cidade de João Pessoa do bairro de Mangabeira.

A importância desse estudo também se revela como momento de "prestação de contas", entendendo ser a nossa obrigação apresentar à sociedade aquilo que ela nos possibilitou: um ensino público e de qualidade junto à Universidade Estadual da Paraíba (UEPB). Por isso, a nossa proposta se revela direcionada à pormenorização das experiências realizadas no citado arquivo enquanto estagiário e orientadora, no intuito de disseminar o conhecimento adquirido durante o período de atuação, que perdurou dois anos ininterruptos (2014-2016), gerando um volume satisfatório de registros das experiências vividas no espaço do arquivo do referido fórum.

Aspectos centrais envolvem as práticas em arquivo nas várias dimensões. Primeiro, a compreensão acerca das complexas atividades vinculadas à gestão dos documentos, que extrapola as quatro paredes do arquivo, abrangendo todo o espaço institucional de produção de informação contínua e, como ambiente orgânico, o controle e a organização passam a ser elementos essenciais nos processos arquivísticos (ROUSSEAU; COUTURE, 1998). Outro desafio é atender às expectativas dos usuários. Num ambiente jurídico, a sua linguagem é especializada e, desse modo, apreendê-la possibilita a aproximação entre o arquivo e o fluxo de documentação dos que deles necessitam.

O objetivo desse estudo foi analisar as práticas arquivísticas desempenhadas no período de atuação de estágio, bem como as orientações realizadas no fórum sediado no bairro de Mangabeira. Por isso, optamos também pela descrição das técnicas e dos procedimentos adotados na realização das atividades, subsidiados pelo campo teórico da Arquivologia.

Desse modo, indagamos: quais foram as práticas adotadas no âmbito dos princípios arquivísticos junto ao Arquivo do Fórum Regional Desembargador José Flóscolo da Nóbrega, localizado no município de João Pessoa?

\section{METODOLOGIA}

$\mathrm{Na}$ seara da metodologia, um estudo de caso refere-se à análise de um objeto numa circunscrição delimitada, a saber, o nosso, vislumbrou o Arquivo do Fórum Desembargador José Flóscolo da Nóbrega, localizado na cidade de João Pessoa do bairro de Mangabeira.

Pelos caminhos da análise científica de uma determinada realidade, torna-se possível maximizar a sua atualização frente à sociedade, contribuindo também para os processos de ensino nas diversas áreas do saber (MINAYO, 2011). Centrados num contexto histórico socialmente específico, as ações praticadas e desenvolvidas foram todas vivenciadas no arquivo em tela (PRODANOV; FREITAS, 2013).

Sua natureza é aplicada, pois, nesse ambiente, lançamos propostas na melhoria dos procedimentos arquivísticos, beneficiando, sobretudo, a precisão e a tramitação do fluxo documental do arquivo do referido fórum. Corroborando com esse entendimento, Prodanov e Freitas (2013) assumem que a pesquisa aplicada objetiva gerar conhecimentos para aplicação prática na solução de problemas.

Inerente a esse tipo de estudo, fez-se necessária a caracterização do campo de atuação e, por isso, a pesquisa assume o caráter descritivo (RICHARDSON et al., 1999). Nessa direção, foi primordial a observação participante, afinal, atuamos como estagiário e orientadora, e o registro diário das atividades realizadas serviu como fonte basilar no relatório das práticas arquivísticas realizadas entre 22 de novembro de 2014 e 22 de novembro de 2016.

Considerando que geramos informações através dos dados levantados em face daquela instituição, esta investigação tem caráter exploratório. Para Prodanov e Freitas (2013), a pesquisa exploratória tem a finalidade de proporcionar informações sobre o assunto investigado.

Além de relatar, sob a ótica arquivística, os fatos relevantes ocorridos nessa trajetória de dois anos, utilizamos de ilustrações e de quadros para facilitar na exposição de 
nossa narrativa. Nesse entorno, praticamos a análise e a interpretação a partir dos dados coletados, aproximando-os aos autores já consolidados na área da Arquivologia. Por tal motivo, este estudo assume abordagem qualitativa. Como ato interpretativo, a leitura de textos científico (a exemplo de livros, periódicos, revista e outros tipos de documentos) foi crucial, incluindo o seu caráter bibliográfico (MINAYO, 2011; PRODANOV; FREITAS, 2013; RICHARDSON et al., 1999).

\section{BREVE REVISÃO DE LITERATU- RA}

A necessidade em transmitir informações perpassa toda a história da humanidade, para tanto, as diversas civilizações utilizaram diferentes suportes para materializar suas ações, tais como a pedra, a tábua de argila, o couro, e outros, que foram registradas em diversas representações, da iconografia aos bits e bytes. Nessa perspectiva, entendemos que a informação é o meio para o desenvolvimento da sociedade, independente do contexto a qual esteja inserida, tornando-se assim o seu sustentáculo. Notoriamente, a informação é a base de muitas sociedades no século XXI e o seu estatuto é garantido, sobretudo, no campo da Ciência da Informação por meio da Arquivologia, da Biblioteconomia e da Museologia (SILVA et al., 2009). Capurro e Hjorland (2007) atentam para a flexibilidade e a penetrabilidade da informação e, por isso, assumem a existência de pluralidade conceitual dependendo da perspectiva adotada.

Corroborando Le Coadic (2004, p. 04), a informação é compreendida enquanto “[...] um conhecimento inscrito (registrado), em forma escrita (impressa ou digital), oral ou audiovisual, em um suporte". A inscrição é realizada em um documento, que assume diferentes configurações a depender da exteriorização da informação realizada pelo sujeito. Na Arquivologia, é comum, mas não exclusivamente, o uso de informação textual, registrada em suporte físico ou digital no âmbito de instituições públicas ou privadas (BELLOTTO, 2006; BRASIL, 1991; SCHELLENBERG, 2006).

Os documentos de arquivo são assim nomeados, pois possuem características singulares, diferenciando-os das fontes de informação presentes nas bibliotecas e nos museus. Segundo Indolfo et al. (1995), documentos de arquivo são aqueles produzidos e/ou recebidos por uma pessoa física ou jurídica, pública ou privada, no exercício de suas atividades, formando um conjunto orgânico e constituindo elementos de prova ou de informação. $\mathrm{Na}$ tentativa de dirimir as dúvidas quanto aos conceitos envolvendo o "documento", elaboramos o Quadro 1 para fins didáticos.

Quadro 1 - Conceitos de documento, documento arquivístico e documento arquivístico digital

\begin{tabular}{|c|l|}
\hline Termo & \multicolumn{1}{c|}{ Conceito } \\
\hline Documento & $\begin{array}{l}\text { Informação escrita independente do material que a compõe, ou seja, o suporte. Podendo } \\
\text { ser uma pedra, um papel ou um equipamento analógico/digital, como: um disquete, CD, } \\
\text { pen drive. }\end{array}$ \\
\hline $\begin{array}{c}\text { Documento } \\
\text { arquivístico }\end{array}$ & $\begin{array}{l}\text { Informação registrada independente do suporte, produzida ou recebida por pessoa física ou } \\
\text { jurídica, pública ou privada no exercício de suas funções, imbuídas de suas relações orgâni- } \\
\text { cas. }\end{array}$ \\
\hline $\begin{array}{c}\text { Documento } \\
\text { arquivístico digital }\end{array}$ & $\begin{array}{l}\text { É documento arquivístico, possuindo forma fixa num suporte analógico ou digital codifi- } \\
\text { cado em digito binário e interpretável por um sistema computacional. }\end{array}$ \\
\hline
\end{tabular}

Fonte: Bellotto (2006); Flores e Lampert (2013); Indolfo et al. (1995); Lopez (2004); Rondinelli (2013) e Schellenberg (2006).

Independente do ambiente em que o documento arquivístico esteja introduzido, em qualquer setor de um órgão, os seus atos só são materializados por via documental e, só desta maneira, é que se tornam comprobatórios e legais. No âmbito jurídico, espaço de nossa análise, as instituições utilizam do registro da informação, formalizando os seus procedimentos e gerando variadas espécies e tipologias de 
acordo com seus atos. No Arquivo do Fórum Desembargador José Flóscolo da Nóbrega, as tipologias documentais mais solicitadas durante o período compreendido entre 2014 e 2016 estão relacionados no Quadro 2.

Quadro 2 - Documentos mais solicitados no Arquivo do Fórum de Mangabeira

\begin{tabular}{|c|c|c|}
\hline Agressão (a menores) & Divórcio litigioso & Livro de carga de advogados \\
\hline Crime com intenção de matar & Homicídio culposo & Livro de protocolo \\
\hline Crime de alta periculosidade & Homicídio doloso & Livro de registro de sentença \\
\hline Crime de pedofilia & Investigação de paternidade & Procedimento ordinário \\
\hline Divórcio consensual & Livro das atas & Roubo (qualificado) \\
\hline
\end{tabular}

Fonte: Dados da pesquisa (2014-2016).

Para o "Dicionário Brasileiro de Terminologia Arquivística", tipologia documental é a

divisão de espécie documental que reúne documentos por suas características comuns no que diz respeito à fórmula diplomática, natureza de conteúdo ou técnica do registro. São exemplos de tipos documentais cartas precatórias, cartas régias, cartas-patentes, decretos sem número, decretos-leis, decretos legislativos, daguerreótipos, litogravuras, serigrafias, xilogravuras. (ARQUIVO NACIONAL, 2005, p. 163).

Segundo Bellotto (2006), a espécie documental é a configuração que assume um documento de acordo com a disposição e o caráter das informações contidas. Como exemplo, temos: ata, carta, decreto, divórcio, fotografia, lei, memorando, ofício, relatório, planta arquitetônica etc.

Caracterizadas as tipologias e as espécies documentais, torna-se necessário estabelecer os procedimentos e os métodos adotados para o controle e a organização dos acervos no arquivo. Geralmente, na elaboração do diagnóstico, já vislumbramos as estratégias relativas à aplicação da Gestão Documental (GD). Neste instrumento, o diagnóstico possibilita a identificação da situação in loco da unidade de informação, pois realizamos o levantamento da situação atual e a lista dos problemas e dos objetivos para superar as dificuldades. Uma vez concretizado o diagnóstico, é possível a otimização das atividades referente aos arquivos como o controle, o fluxo, a organização, o tratamento e o arquivamento dos documentos. Similar a lógica aplicada no processo de diagnóstico, Cornelsen e Nelli (2006) sugerem o estudo dos fundos e a elaboração de um projeto para preencher as lacunas identificadas.

Conforme a Lei de $\mathrm{n}^{\circ}$. 8.159 (BRASIL, 1991), no artigo $3^{\circ}$, a GD é definida como o conjunto de procedimentos e técnicas no tocante a produção, tramitação, uso, avaliação e arquivamento do documento, nas fases corrente e intermediária, visando a sua eliminação ou recolhimento para guarda permanente.

Assim, o funcionamento de um arquivo prescinde da aplicação de princípios e de critérios arquivísticos, incluindo todo ciclo de vida dos documentos, as fases corrente, intermediária e permanente, ou seja, valer-se da GD para garantir: segurança $\mathrm{e}$ rapidez no acesso aos arquivos e às informações recuperadas; eficiência e eficácia na administração pública ou privada sobre seus acervos; controle do fluxo de documentos e a organização dos arquivos; racionalização da produção dos documentos; normalização nos procedimentos para avaliação, transferência, recolhimento, guarda e eliminação de documentos e preservação do patrimônio documental (BERNARDES; DELATOR-RE， 2008; SCHELLENBERG, 2006). 
No âmbito da GD, é importante destacar a necessária elaboração dos instrumentos de gestão, a saber, o Plano de Classificação de Documentos (PCD) e a Tabela de Temporalidade de Documentos (TTD). Estes dispositivos visam organizar, representar, controlar e recuperar os documentos de uma instituição.

O Plano de Classificação de Documentos de Arquivo resulta da atividade de classificação que recupera o contexto de produção dos documentos de arquivo agrupando-os de acordo com o órgão produtor, a função, a subfunção e a atividade responsável por sua produção ou acumulação e a Tabela de Temporalidade de Documentos de Arquivo resulta da atividade de avaliação, que define prazos de guarda para os documentos em razão de seus valores administrativo, fiscal, jurídico-legal, técnico, histórico, autoriza a sua eliminação ou determina a sua guarda permanente (BERNARDES; DELATORRE, 2008, p. 11).

Todos os fatores descritos explicitam os métodos e as ações referentes às atividades desenvolvidas para o devido funcionamento de qualquer arquivo. Esses parâmetros são essenciais para a implementação de uma GD eficiente e eficaz nas unidades de informação.

\section{DESCREVENDO O ARQUIVO DO FÓRUM DESEMBARGADOR JOSÉ FLÓSCOLO DA NÓBREGA}

A criação e instalação do Superior Tribunal de Justiça (STJ) no Estado da Paraíba ocorreu em 1891. A época, o governador Venâncio Neiva nomeou, além de desembargadores, outros integrantes que compunha a magistratura paraibana para a constituição do Tribunal. As ramificações referentes às nomeações ocorreram em diversos municípios da Paraíba, a falar, Bananeiras, Guarabira, Pilar, Santa Rita, entre outros. $\mathrm{Na}$ ocasião, um fato curioso foi a nomeação de Aureliano Filgueiras para os cargos de arquivista e amanuense (TRIBUNAL..., 2005a), completando o quadro de funcionários da instituição. No século XIX, o reconhecimento da profissão foi algo que nos chamou a atenção.

Obviamente, um acontecimento dessa magnitude logo ganharia um lastro na imprensa por seu ineditismo no estado e significado social, administrativo e político. Com isso, a população paraibana se beneficiava em diversos aspectos, surgindo órgãos ligados ao poder judiciário, como a Casa de Justiça e a popularização dos cartórios (TRIBUNAL..., 2005a).

Um ano depois de sua criação, em 1892, o Tribunal amargou a sua dissolução em função de uma série de acontecimentos políticos. Contudo, foi realizada uma reorganização do Poder Judiciário na Paraíba por meio da promulgação de Carta Magna que garantia, pelo menos no papel, com sede na capital, a existência do Tribunal de Justiça do Estado da Paraíba (TJPB), vinculada ao Superior Tribunal (TRIBUNAL..., 2005b). As turbulências no campo da política foram apaziguando e, em meados de 1982, o TJPB retorna às atividades.

No dia 11 de fevereiro do ano seguinte (1893), o Presidente do Estado editou o Decreto $\mathrm{n}^{\circ}$. 8, designando o dia 23 de fevereiro para a instalação do novo Tribunal. (TRIBUNAL..., 2005c, p. 02).

O TJPB é um órgão que presta serviços jurídicos e tem como missão

[...] concretizar a justiça, por meio de uma prestação jurisdicional acessível, célere e efetiva. [Sua visão] é alcançar o grau de excelência na prestação de seus serviços e ser reconhecida pela sociedade como uma instituição confiável, tangível e justa, na garantia do exercício pleno da cidadania e promoção da paz social (TRIBUNAL..., 2005a, p. 01).

Busca ainda alguns atributos de valores para a sociedade, como: credibilidade, modernidade, acessibilidade, 
transparência, responsabilidade social e ambiental, imparcialidade, ética e probidade. Nesse sentido, com a estabilidade do Tribunal na Paraíba surgiam as comarcas para lhes garantir suporte no tangente à administração e ao monitoramento dos preceitos legais no estado.

O Fórum Desembargador José Flóscolo da Nóbrega foi criado em 15 de Outubro de 2010 com a intenção de descentralização da comarca da capital (TJPB), possuindo seis varas regionais com três seções e dois juizados especiais. Apesar de ter sido criado em 2010, a instituição detém em seu acervo documentação com data mais antiga que sua gênese, ou seja, documentos denotados desde a década de 1980. Isto ocorre porque a comarca funcionava em outro local e só há seis anos foi transferida para o atual endereço.

$\mathrm{O}$ arquivo atendia, exclusivamente, ao Cartório Unificado, formado por seis varas distritais, a saber, $1^{\text {a }}$ Vara da Seção Cível, $2^{a}$ Vara da Seção Família, $3^{\text {a }}$ Vara da Seção Criminal, $4^{a}$ Vara da Seção Cível, $5^{\text {a }}$ Vara da Seção Família e $6^{a}$ Vara da Seção Criminal. Tais varas esquematizam a divisão do arquivo no Fórum, possuindo duas varas para cada seção, então: primeira $\left(1^{a}\right)$ e quarta $\left(4^{a}\right)$ Varas - Seção Cível, segunda $\left(2^{a}\right)$ e quinta $\left(5^{a}\right)$ Varas - Seção Família, terceira $\left(3^{a}\right)$ e sexta $\left(6^{a}\right)$ Varas - Seção Criminal. Respectivamente, o arquivo do primeiro $\left(1^{\circ}\right)$ e segundo $\left(2^{\circ}\right)$ juizados não são pertencentes ao Cartório Unificado e, por isso, não foram objetos de análise da nossa pesquisa.

Os demais setores possuem uma organização própria sobre sua documentação. Contudo, o arquivo atende às demandas do cartório, englobando todos os procedimentos referentes à interlocução entre eles, nesse caso, também aos documentos-processos existentes, a inspeção e sua manutenção.

\section{INTERVENÇÕES E SUGESTÕES}

Para diferenciar os processos de cada vara, os documentos eram separados por capilhas com um sistema de cores distintas: azuis para processos das varas cíveis, amarelas para varas de família e brancas para as criminais, conforme demonstrado no Quadro 3.

Quadro 3 - Identificação das capilhas separadas por cores

\section{Capilhas azuis: $1^{\mathrm{a}}$ e $4^{\mathrm{a}}$ Varas da Seção Cível}

Capilhas amarelas: $2^{\mathrm{a}}$ e $5^{\mathrm{a}}$ Varas da Seção Família

Capilhas brancas: $3^{\mathrm{a}}$ e $6^{\mathrm{a}}$ Varas da Seção Criminal

Fonte: Dados da pesquisa (2014 a 2016).

Como os processos mudavam de vara dependendo do assunto (processos que antes tramitavam pela área cível, tornou-se criminal, por exemplo), também foi criada a identificação por etiquetas coloridas fixadas no lado esquerdo da capa dos documentos, como ilustrado no Quadro 4.

Quadro 4 - Esquema de cores das etiquetagens nos processos

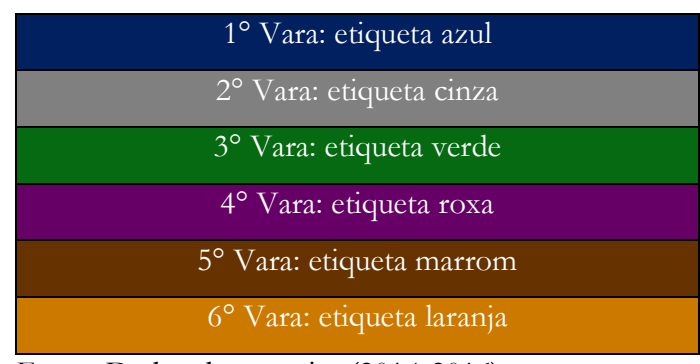

Fonte: Dados da pesquisa (2014-2016).

As cores do Quadro 4 seguem o padrão usado em cada processo conforme a descrição acima: $1^{\mathrm{a}}$ Vara - azul; $2^{\mathrm{a}}$ Vara cinza; $3^{\mathrm{a}}$ Vara - verde; $4^{\mathrm{a}}$ Vara - roxa; $5^{\mathrm{a}}$ Vara - amarela; $6^{\circ}$ Vara - laranja. As identificações des-tacadas no sistema colorido foi uma iniciativa do TJPB no ano de 2013. A ideia deste projeto ocorreu para evitar o extravio ou o arquivamento equivocado dos processos, facilitando a visualização.

No Quadro 5, contribuindo para a agilidade e para a padronização dos procedimentos arquivísticos, foi elaborado um funcionograma, descrevendo as atividades realizadas no arquivo. 
Da experiência à análise arquivísticas: um estudo de caso realizado no Arquivo do Fórum Regional Desembargador José Flóscolo da Nóbrega (João Pessoa - Paraíba)

Quadro 5 - Funcionograma das atividades no arquivo realizados no arquivo do fórum de Mangabeira

\begin{tabular}{|c|c|}
\hline Atividade & Descrição \\
\hline Arquivamento de processos & $\begin{array}{c}\text { Encaminhamento dos processos para o arquivo através do sistema, reali- } \\
\text { zando o arquivamento de acordo com a vara e a numeração adequada. }\end{array}$ \\
\hline $\begin{array}{c}\text { Encaminhamento de processos } \\
\text { solicitados pelo cartório }\end{array}$ & $\begin{array}{c}\text { Após a localização dos processos solicitados, a documentação era enca- } \\
\text { minhada ao Cartório Unificado. }\end{array}$ \\
\hline $\begin{array}{c}\text { Higienização de documentos } \\
\text { Identificação de caixas-arquivo }\end{array}$ & $\begin{array}{c}\text { Separação dos processos mais antigos para a troca das capas e sua identi- } \\
\text { ficação. }\end{array}$ \\
\hline $\begin{array}{c}\text { Localização de documentos } \\
\text { solicitados via sistema }\end{array}$ & $\begin{array}{c}\text { Após a solicitação de processos pelo cartório, os funcionários do arquivo } \\
\text { (estagiário e chefe) verificavam no sistema o número de caixa e em qual } \\
\text { vara estava localizada a documentação. }\end{array}$ \\
\hline Organização do arquivo & $\begin{array}{c}\text { Facilitação da localização para atender as necessidades do cartório com } \\
\text { rapidez. }\end{array}$ \\
\hline $\begin{array}{c}\text { Padronização do arquivo } \\
\text { Troca de capilhas nos processos }\end{array}$ & $\begin{array}{c}\text { Assegura organização e segurança da informação do setor de arquivo, } \\
\text { usando etiquetas (tarjas coloridas) para as seis varas do arquivo. }\end{array}$ \\
\hline $\begin{array}{c}\text { Quando as capas dos processos estiverem danificadas, realizar a troca } \\
\text { para a preservação dos documentos. }\end{array}$ \\
\hline $\begin{array}{c}\text { Na transferência de processos de uma vara para outra, proceder com a } \\
\text { troca de etiquetas. }\end{array}$ \\
\hline
\end{tabular}

Fonte: Dados da pesquisa (2014-2016).

Com base na descrição das atividades (Quadro 5), foram identificadas as atribuições dos estagiários no arquivo, conforme Quadro 6.

Quadro 6 - Atribuições no arquivo

\begin{tabular}{|l|l|}
\hline Análise documentária & Identificação de caixa-arquivo \\
\hline Arquivamento processual & Identificação de falta de partes de processos \\
\hline Arranjo documental & Inspeção dos processos \\
\hline Avaliação documental & Localização de processos solicitados \\
\hline Classificação documental & Organização do Arquivo \\
\hline Conservação dos documentos & Padronização do Arquivo \\
\hline Controle documental & Preservação documental \\
\hline Descrição documental & Recebimento documental \\
\hline Distribuição de caixas arquivadas para sua respectiva vara & Registro documental \\
\hline Encaminhamento da documentação solicitada pelo cartório & Seleção documental \\
\hline Higienização dos documentos & Separação dos processos solicitados \\
\hline
\end{tabular}

Fonte: Dados da pesquisa (2014-2016).

Relativo à atividade do "arquivamento físico" dos processos no Arquivo do Fórum de Mangabeira acontecia da seguinte forma: os processos eram acondicionados em caixas poliondas nas estantes de aço nas salas pertencentes ao
Arquivo. Nelas, eram identificadas as caixas com etiquetas estabelecidas pelo Tribunal de Justiça recebendo a numeração da vara e da logomarca da instituição. Até 2016, último ano que realizamos atividades junto ao órgão, o Fórum convivia com a tramitação 
documental por meio de dois suportes: o físico e o digital. Neste meio, usávamos um sistema computacional cujo arquivamento era realizado via planilha, possibilitando localizar e re-arquivar de forma ágil os processos. A finalidade do sistema era primordialmente cadastrar o número dos processos na rede.

Como já citado, a comunicação do Arquivo com o Cartório era intensa, necessitando de atenção redobrada, pois os processos solicitados ao Arquivo pelos usuários eram registrados na planilha online e no livro de protocolo, devidamente assinado. $\mathrm{Na}$ GD, é primordial o uso do PCD e da TTD, mas, como essas não existiam no Fórum, não havia eliminação e nem recolhimento dos documentos. Desse modo, parte considerável destes processos encontravam-se guardados e desgastados pela ausência de tratamento e de higienização. Assim, quando requisitados, eram higienizados (Fluxograma 1) para ser acessado e usado; retornando ao Arquivo, eram guardados em caixas sinalizadas.

Fluxograma 1 - Etapas da higienização dos documentos do arquivo do Fórum de Mangabeira

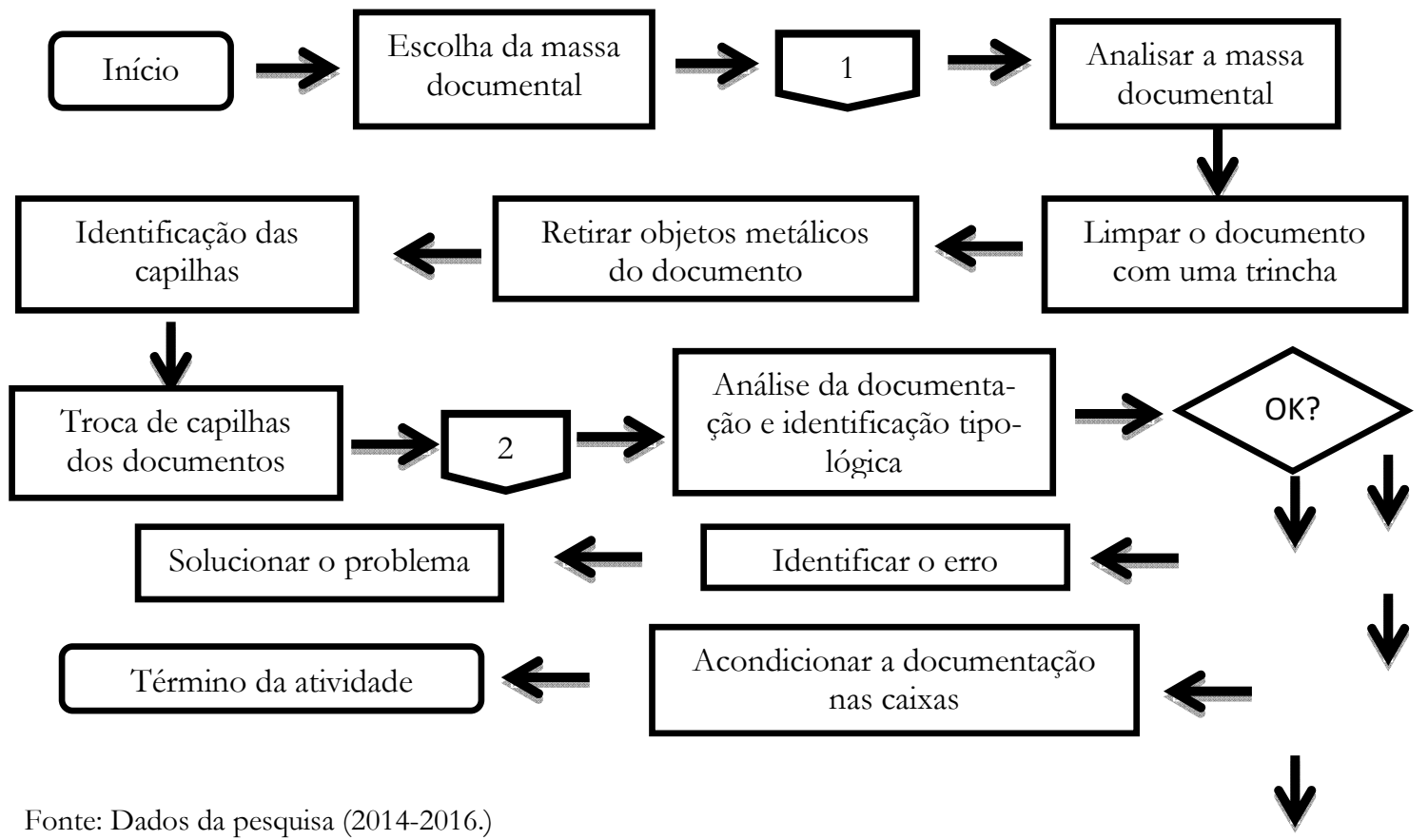

A organização sistemática é outra atividade realizada pelo setor, servindo para facilitar e manter a ordenação dos documentos. Este procedimento era feito por meio de um número único atribuído ao processo e à caixa-arquivo. Esse fluxo de atividades diária associada ao uso do Siscom-web (sistema digital do TJPB) facilitava e agilizava a localização física dos processos. Outra vantagem do Siscom-web era a imediata recuperação dos metadados dos documentos, contudo, isso dependia da política de catalogação definida pelos gestores quanto ao preenchi- mento parcial ou total das informações contidas nos processos.

A avaliação documental também é outra atividade desempenhada com certas ressalvas. Segundo o "Dicionário Brasileiro de Terminologia Arquivística", trata do

[...] processo de análise de documentos de arquivo, que estabelece os prazos de guarda e a destinação, de acordo como os valores que lhes são atribuídos. (ARQUIVO NACIONAL, 2005, p. 35). 
É um procedimento de extrema importância, pois evita o acúmulo de Massa Documental Acumulada (MDA), maximizando o espaço físico e digital do arquivo. $\mathrm{O}$ problema em relação à realização da avaliação no Arquivo foi a falta de instrumentos como o PCD e a TTD no sentido de proceder de modo seguro, do ponto de vista jurídico, com a eliminação dos documentos.

Essas foram as práticas desenvolvidas no Arquivo do Fórum de Mangabeira. Porém, percebemos que a sua existência se vinculava a suprir diretamente as demandas do Cartório Unificado. Outras atividades que poderiam ser funções do Arquivo, como planejamento e produção documental, não estavam vinculadas a este setor. Podemos asseverar que, mesmo diante das amarras institucionais, realizamos nosso trabalho de forma plenamente exequível, facilitando e auxiliando os usuários na busca da informação requisitada.

A partir do discorrido no percurso do nosso relato, podemos constatar a necessidade do arquivista nas instituições de cunho jurídico. Os momentos de estágio e de orientação, que perfizeram dois anos, foram fundamentais para perceber como a teoria flui nas práticas cotidianas do arquivo. Seja físico ou digital, a funcionalidade do documento é imprescindível numa organização; é o registro que assegura a possibilidade de legalidade dos atos.

Foi com a intervenção dos estagiários do Arquivo, em parceria com os servidores efetivos do setor, ressaltando que não eram graduados em Arquivologia, que os procedimentos técnicos passaram por reestruturação de modo a otimizar as atividades realizadas. Os ambientes reservados aos arquivos no fórum eram totalmente insalubres e fora dos parâmetros arquivísticos: demasiada luminosidade solar, paredes com rachaduras em função de infiltração e a existência de mofo. $\mathrm{O}$ volume de documentos, principalmente da Vara Criminal, era outro obstáculo a superar, pois inviabilizava a locomoção e a organização dentro do espaço de trabalho.

Prosseguindo com as atividades já norteadas pela equipe anterior de estagiários de Arquivologia no referido arquivo, atuamos também no sentido da melhoria continuada, principalmente, no que se refere às condições de trabalho. Durante o período de 2014 a 2016, éramos quatro estagiários no setor.

Conseguimos, enquanto equipe, que os objetos e as ferramentas oriundos de crimes fossem transferidos dos arquivos para sala específica, contendo, incluso, cofre de segurança. Em relação aos livros do Fórum, desprovidos de organização e de acondicionamento corretos, foram higienizados, etiquetados, descritos (incluindo tipologia e data) e devidamente dispostos nas estantes para uso. Por meio de insistentes buscas pelo Siscom-web, conseguimos praticamente tornar nulo o extravio dos processos, além de localizar os que se encontravam desaparecidos. Em particular, atividade árdua e minuciosa, porém imprescindível para a instituição e os seus usuários.

Figura 1 - Layout para sala de arquivo em plantas baixas e em 3D

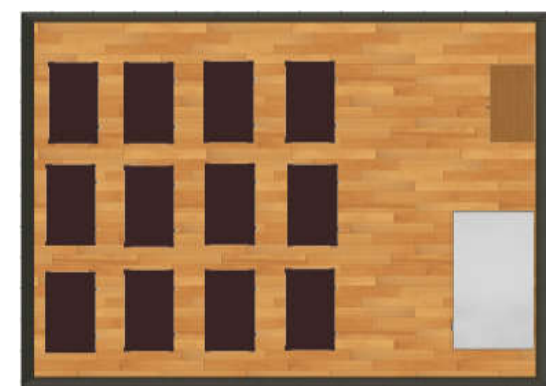

Fonte: Autodesk Homestyler (2016).

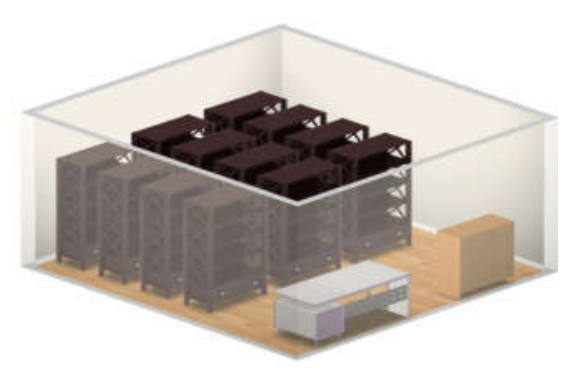


O intento da equipe de estagiários foi a solicitação de ambiente de trabalhos seguindo os parâmetros arquivísticos: de mesas e cadeiras adequadas ergonomicamente a estantes apropriadas e em quantidade suficiente para acomodar os documentos.
Fazendo uso do programa de design gráfico nominado Autodesk. Homestyler (2016), elaboramos e sugerimos a arquitetura em planta baixa e em 3D para o setor de arquivo. As Figuras 1 e 2 apresentam o layout do citado setor no ano de 2016.

Figura 2 - Sugestão do novo layout para o arquivo físico, visualizado em planta baixa e em 3D

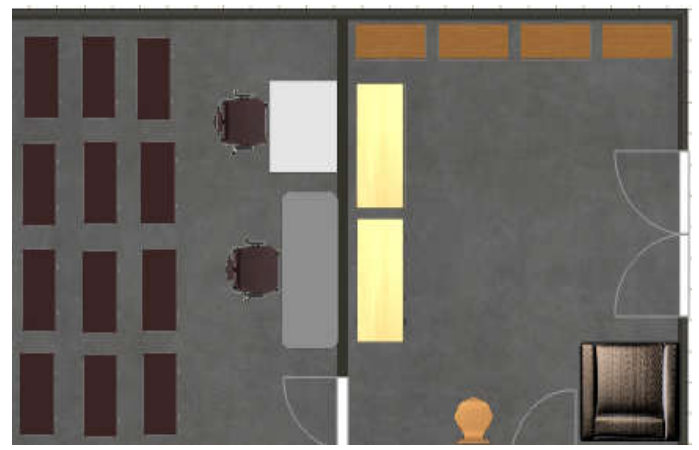

Fonte: Autodesk Homestyler (2016).

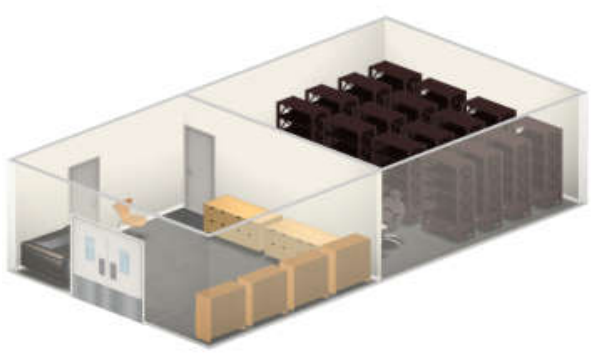

ções para a execução laboral, fazendo uso do mesmo programa de design, sugerimos as modificações no layout do Arquivo, conforme as Figuras 2 e 3. inapropriado para o desenvolvimento das atividades arquivísticas. A partir dessa realidade e da necessidade de melhores adequa-

Figura 3 - Sugestão do novo layout para o arquivo, sala da chefia e atividades informatizadas, visualizado em planta baixa e em 3D

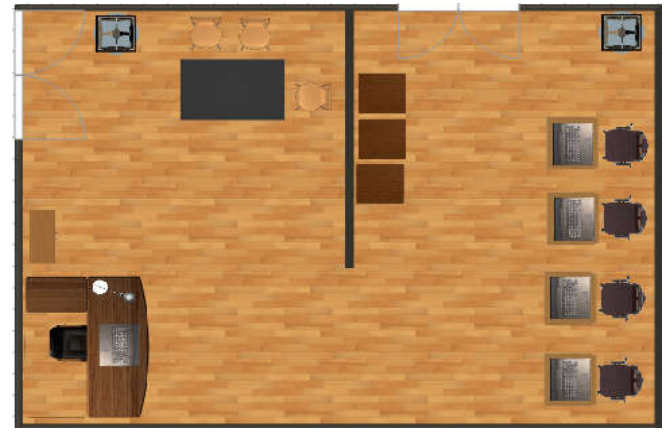

Fonte: Autodesk Homestyler (2016).

As sugestões contaram também com as especificações envolvendo a metragem recomendada e os mobiliários adequados. $\mathrm{Na}$ Figura 2, atentamos para o cuidado em separar o ambiente relativo à execução das atividades técnicas do espaço resguardado ao acondicionamento dos documentos físicos. Além de minimizar a insalubridade, essa necessária readequação envolve a segurança

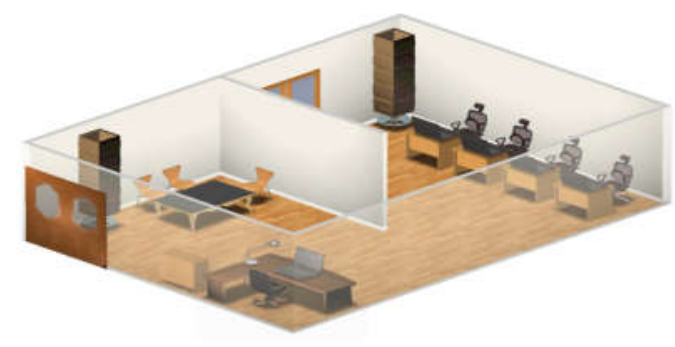

quanto ao acesso aos documentos. Outro aspecto relevante, apresentado na Figura 3, é o espaço resguardado para as atividades vinculadas ao uso do sistema informatizado.

\section{CONSIDERAÇÕES FINAIS}

O conhecimento adquirido durante o período de estágio e de orientação foi pri- 
mordial para formação acadêmica do discente quanto para a docente. Cada prática realizada no Arquivo foi única. Para além das atividades técnicas realizadas, ter a possibilidade de sugerir modificações institucionais para otimização das condições de trabalho, tornou o aprendizado dinâmico.

Dificuldades não é dissabor dos arquivistas, nas bibliotecas também são enfrentados desafios cotidianos, assim como em qualquer outra área. Contudo, ressaltamos que o apoio constante da Diretoria do Fórum e do Cartório foi substancial, principalmente, por tornar possível a implementação de propostas para a otimização do setor de arquivo do Fórum Regional Desembargador José Flóscolo da Nóbrega, localizado no município de João Pessoa.

Nesse sentido, o objetivo do nosso trabalho foi alcançado, apresentando o nosso cotidiano, além do desenvolvimento de atividades laborais. Vale ressaltar que o uso do registro diário por meio da observação dos acontecimentos viabilizou a produção desse estudo com riqueza de detalhes.

Estamos cientes que, embora não estejamos expondo ao debate da arquivística algo inédito, trata-se do compartilhamento de pesquisa aplicada que se caracteriza por particularidades contextuais da prática arquivística. Para nós, o desafio era algo experienciado no dia a dia, sentimento talvez percebido por outros funcionários. Nessa direção, a rotina que tivemos, quiçá, pode servir de auxílio para profissionais que atuam nos arquivos. Acrescentamos que o fazer arquivístico não se limita apenas à implementação de procedimentos e de métodos no gerenciamento da informação. A busca por melhores condições de trabalho e o nosso reconhecimento nas instituições fazem parte de uma luta constante ainda presente na realidade brasileira.

\title{
ARCHIVISTIC ANALYSIS AND PRACTICES: \\ Case study in the Archives of the Regional Forum Judge José Flóscolo da Nóbrega (João Pessoa - Paraíba)
}

\begin{abstract}
The complex document management activity covers the whole institutional space of production, organization, control and use of archival documentation. The objective of the study was to analyze the archival practices performed during the internship period (between November 22, 2014 and November 22, 2016), as well as the guidelines made in the file of the regional forum of the Judge José Flóscolo da Nóbrega, located in the municipality of João Pessoa. Methodologically, the investigation assumed a descriptive and exploratory character; its applied nature, has launched proposals to improve archive practices. The participant observation, the daily record and the report of the activities performed were used as a data collection instrument. Interpreting reality in the light of the authors already consolidated in the field of Archivology, the study was anchored in a qualitative approach. As a result, it was presented a description of the techniques and procedures adopted in the accomplishment of the activities, subsidized by the theoretical field of Archivology, bringing precision and processing of the documentary flow of the archive of said forum. It is concluded that archival archiving is not limited only to the implementation of procedures and methods in information management. The search for better working conditions and recognition in institutions is a constant struggle of the archivists, still part of the Brazilian reality.
\end{abstract}

Keywords

Archive of the Court of Justice of Paraiba. Forum Judge José Flóscolo da Nóbrega. Document management.

Artigo recebido em 17/06/2018 e aceito para publicação em 11/08/2018

\section{REFERÊNCIAS}

ARQUIVO NACIONAL (Brasil). Dicionário brasileiro de terminologia arquivística. Rio de Janeiro: Arquivo Nacional, 2005.
AUTODESK HOMESTYLER. 2016. Disponível em:

$<$ http://pt.homestyler.com/designer>.

Acesso em: 21 fev. 2018. 
BELLOTTO, H. L. Arquivos permanente: tratamento documental. 4. ed. Rio de Janeiro: FGV, 2006.

BERNARDES, I. P.; DELATORRE, H. Gestão documental aplicada. São Paulo: Arquivo Público do Estado de São Paulo, 2008.

BRASIL. Lei ${ }^{\circ} 8.159$, de 8 de janeiro de 1991. Dispõe sobre a política nacional de arquivos públicos e privados e dá outras providências. Brasília: Planalto, 1991. Disponível em:

$<$ http://www.planalto.gov.br/ccivil_03/leis /L8159.htm>. Acesso em: 15 fev. 2018.

CAPURRO, R.; HJORLAND, B. O conceito de informação. Perspectiva em Ciência da Informação, Belo Horizonte, v. 12, n. 1, p. 148-207, jan./abr. 2007.

CONELSEN, J. M.; NELLI, V. J. Gestão integrada da informação arquivística: o diagnóstico de arquivos. Arquivística.net, v. 2, n. 2, p. 70-84, ago./dez. 2006. Disponível em:

$<$ http://www.brapci.inf.br/index.php/articl e/download/6718>. Acesso em: $15 \mathrm{fev}$. 2018.

FLORES, D.; LAMPERT, S. R.. As funções de produção, classificação e avaliação de documentos arquivísticos no software $\mathrm{Nu}$ xeo Document Management. Informação arquivística, Rio de Janeiro, v. 2, n. 1, p. 4164. jan/jun. 2013.

INDOLFO, A. C. et al. Gestão de documentos: conceitos e procedimentos básicos. Rio de Janeiro: Arquivo Nacional, 1995.

LE COADIC, Y. F. A Ciência da Informação. 2. ed. rev. e atual. Brasília: Briquet de Lemos, 2004.

LOPEZ, A. P. A. Princípios arquivísticos e documento digitais. Revista Arquivo Rio Claro, Rio Claro, n. 2, p. 70-85. 2004.
MINAYO, M. C. S. (Org.). Pesquisa social: teoria, método e criatividade. 30. ed. Rio de Janeiro: Vozes, 2011.

PRODANOV, C. C.; FREITAS, E. C. Metodologia do trabalho científico: métodos e técnicas da pesquisa do trabalho acadêmico. 2. ed. Novo Hamburgo: Feevale, 2013.

RICHARDSON, R. J. et al. Pesquisa social: métodos e técnicas. São Paulo: Atlas, 1999.

RONDINELLI, R. C. O documento arquivístico ante a realidade digital: uma revisitação conceitual necessária. Rio de Janeiro: FGV, 2013.

ROUSSEAU, J. Y.; COUTURE, C. Os fundamentos da disciplina arquivísticas. Lisboa: Publicações Dom Quixote,1998.

SCHELLENBERG, T. R.. Arquivos modernos: princípios e técnicas. 6. ed. Rio de Janeiro: FGV, 2006.

SILVA, A. M. et al. Arquivística: teoria e prática de uma Ciência da Informação. 3. ed. Porto: Afrontamento, 2009.

TRIBUNAL DE JUSTIÇA DA PARAÍBA. Histórico de Tribunal. João Pessoa: TJPB, 2005a. Disponível em: $<$ http://www.tjpb.jus.br/institucional/histo rico-do-tribunal/>. Acesso em: 15 fev. 2018.

Histórico de Tribunal. João Pessoa: TJPB, 2005b. Disponível em: $<$ https://www.tjpb.jus.br/institucional/hist orico-do-tribunal/primeira-fase/>. Acesso em: 15 fev. 2018.

Histórico de Tribunal. João Pessoa: TJPB, 2005c. Disponível em: $<$ https://www.tjpb.jus.br/institucional/hist orico-do-tribunal/segunda-fase/>. Acesso em: 15 fev. 2018. 